\title{
SEWAGE PERFORMANCE OF A NEW TYPE OF FLAP FILTER
}

\author{
Zhenji Liu ${ }^{1 *}$, Kai Shi ${ }^{1}$, Man $\mathrm{Li}^{1}$, Yan Xie ${ }^{1}$ \\ ${ }^{1 *}$ Corresponding author. College of Water Conservancy and Civil Engineering, Shihezi University/ Shihezi, China. \\ E-mail: 39080706@qq.com | ORCID ID: https://orcid.org/0000-0001-7254-2501
}

\section{KEYWORDS}

flap-type mesh filter, discharge time, pressure difference, cleanliness, sewage effect.

\begin{abstract}
The drainage performance of a mesh filter determines the water consumption degree of the filter and the efficiency of the next work cycle. Through analysis, we found that the influent flow rate and the sediment content of the influent were important influencing factors. This experiment focused on the drainage time, pressure difference, and cleanliness to investigate the drainage performance of a new type of flap filter. The results showed that with increasing inlet flow rates, the time to discharge the effluent decreased, and the time required for the difference between the primary and secondary sewage pressures to reach a constant level was shorter. The cleanliness and drainage effects were improved. To verify this, we established mathematical models of sewage discharge time, sewage pressure difference, and sewage cleanliness based on the mass conservation law. The results showed that the relative error between the fitting calculation results and the experimental results was small, and the formula fit was over $95 \%$. In the actual work, to achieve efficient sewage discharge under the condition of low sewage discharge and low water consumption, the discharge flow rate was set to $180 \mathrm{~m}^{3} \mathrm{~h}^{-1}$, and the sewage discharge time was set to $50 \mathrm{~s}$. Under this condition, the sewage cleanliness reached above $97 \%$.
\end{abstract}

\section{INTRODUCTION}

Water resources constitute an irreplaceable basic element in agricultural development, but the current scarcity of water resources limits the sustainable development of agricultural production. How to conserve and efficiently utilize water resources has become a necessary factor to promote agricultural development (Hamududu \& Ngoma 2020; Li et al. 2020; Rashid et al. 2020). Microirrigation technology is the best way to save water resources and provides a strong guarantee for the development of water-saving irrigation (de-Vito et al. 2019). As the core component of microirrigation systems, filters plays the important role of removing sediment particles and other suspended impurities from the muddy water source (Zong et al. 2015). Many scholars have analysed the head loss and sewage time of mesh filters through a large number of experimental studies, including filtration tests and sewage tests. The sewage time is defined as the required time for a screen filter to complete sewage cleaning. Many relevant research results have been obtained on the head loss and sewage time of mesh filters. First, many scholars have studied changes in the head loss of mesh filters during the filtration process. The results have shown that the head loss of mesh filters is related to the water flow rate, the sand content of the water and the porosity of the filter and that the pressure difference between the water inlet and outlet changes exponentially with time (GarcíaNieto et al. 2018; Bové et al. 2015; Elbana et al. 2013; Piecuch et al. 2013; Yurdem et al. 2010; Duran-Ros et al. 2009; Puig-Bargués et al. 2005). At the same time, previous studies have also analysed the dissolved oxygen in the filtering process of the mesh filter, the turbidity of the water source after filtration, the flow change after filtration, and the relationship between head loss and filter blockage. By combining analysis models, such as Gaussian process regression (GPR), artificial neural networks (ANNs), multivariable linear regression (MLR), gene expression programming (GEP), MATLAB and other dimensional analysis methods, changes in the head loss of mesh filters over time have been analysed (García-Nieto et al. 2020; Mesquita et al. 2019; Bounoua et al. 2016; García-Nieto et al. 2016; Martí et al. 2013; Elbana et al. 2012). Second, most scholars

${ }^{1}$ College of Water Conservancy and Civil Engineering, Shihezi University/ Shihezi, China.

Area Editor: Danilton Luiz Flumignan

Received in: 5-22-2020

Accepted in: 2-12-2021 
analysed the cleaning time of mesh filters through various test methods. By combining the sewage efficiency and sewage pressure difference, the sewage discharge process of mesh filters was studied, the influencing factors of the sewage process were determined, the sewage time value under various working conditions was measured, and the actual sewage time of the mesh filter was determined with guidance (de-Deus et al. 2020; Zong et al. 2019). Although there have been many reports on filters, new types of flap filters have rarely been studied. In particular, there is no relevant study on the sewage discharge time and sewage pressure difference during the sewage discharge process, and the sewage discharge effect of new filters has not been reported. Herein, a new type of flap-type mesh filter was studied focusing on the change in the drainage time and pressure difference during the drainage process of the filter; this type of study can provide guidance for the drainage of the flap-type mesh filter. By analysing the law of the sewage discharge time and the pressure difference of sewage discharge, the optimal sewage discharge time under each working condition can be accurately determined, which helps to avoid the problems of incomplete sewage discharge and

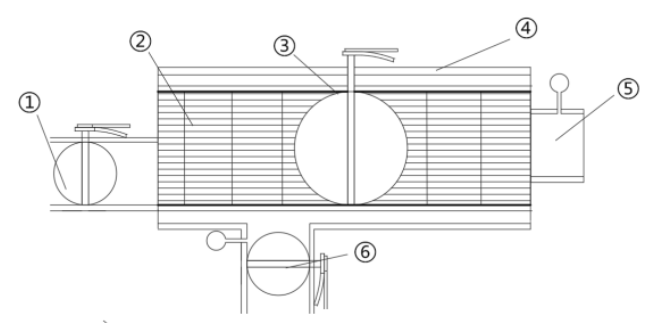

(1) Sewage outlet; (2) Filter screen; (3) Rotatable flap; (4) Water outlet; (5) Water inlet; (6) Water outlet 1-1 Structure of the flap filter

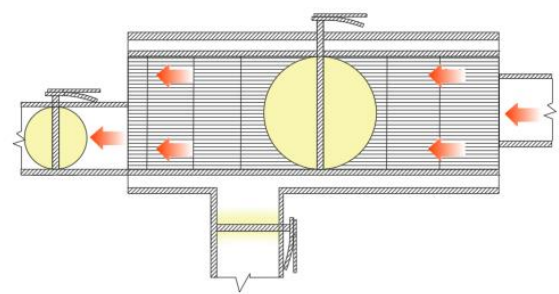

1-3 Schematic diagrams of the internal water flow in the first stage of the flap filter considerable water consumption caused by insufficient sewage discharge times and excessively long sewage discharge times, respectively.

\section{MATERIAL AND METHODS}

\section{Working principle of the flap filter}

\section{Filter structure}

Figure 1-1 shows the structure of the flap filter, which is composed of a filter housing unit, a filter element and a $90^{\circ}$ rotating flap set in the middle of the filter. Figure 1-2 shows a schematic diagram of the internal water flow in the filtering process of the flap filter. Figures 1-3 and 1-4 show schematic diagrams of the internal water flow in the first and second flap filter stages, respectively. The dimensions of the main components of the flap filter are as follows: the inner diameter of the water inlet is $200 \mathrm{~mm}$, the inner diameter of the water outlet is $200 \mathrm{~mm}$, the inner diameter of the sewage outlet is $150 \mathrm{~mm}$, the filter housing length is $1700 \mathrm{~mm}$, the diameter is $380 \mathrm{~mm}$, the length of filter screen is $1520 \mathrm{~mm}$, and the inner diameter is $280 \mathrm{~mm}$. The rated working flow of the filter is set to $140 \mathrm{~m}^{3}$ $h^{-1}-220 m^{3} h^{-1}$.

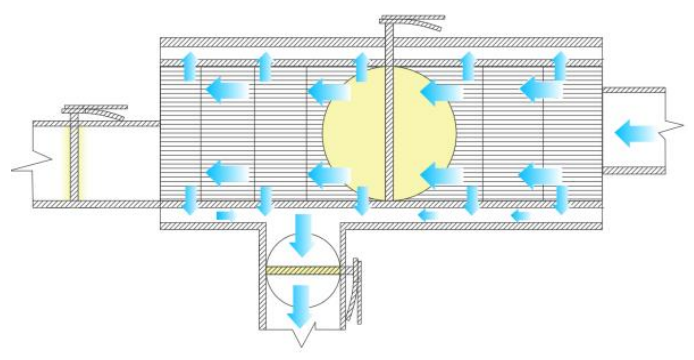

1-2 Schematic diagram of the internal water flow in the filtering process of the flap filter

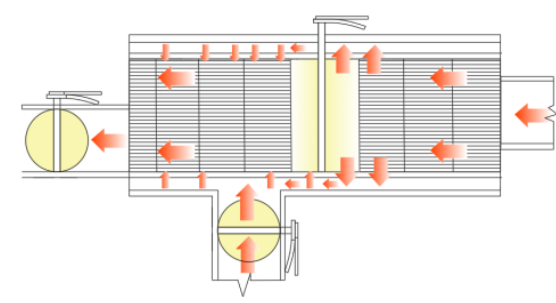

1-4 Schematic diagrams of the internal water flow in the second stage of the flap filter

FIGURE 1. Structure of the flap filter and schematic diagram of the internal water flow of the flap filter.

\section{Working principle of the filtration process}

When the flap filter is working (Figure 1-2), the flap should be kept open, and the drain outlet should remain closed. Sandy irrigation water deposited in the sedimentation tank enters the filter through the water inlet and is then filtered from the inside of the filter to the outside. Particles larger than the filter aperture are intercepted inside the filter and form a pile. The fresh filtered water enters the designated irrigation system from the water outlet. Due to the accumulation of sediment, a pressure difference is formed inside and outside the filter screen. When the pressure difference exceeds a pre-set threshold (to study the change rule of the flap filter throughout the working cycle, this test sets the sewage start-up pressure difference as the peak pressure difference corresponding to the sand-containing 
filtering conditions), the sewage discharge work is initiated.

\section{Working principle of the sewage process}

The drainage process of the flap filter can be divided into two stages. The first stage is the primary discharge stage (Figure 1-3). In this stage, the flap is kept open, the sewage valve is open, and the water outlet valve is closed. Clean water enters the filter from the water inlet, carries sediment impurities between the water inlet and the flap, and forms a pile between the flap and the water outlet. The second stage is the secondary discharge stage (Figure 1-4). After the primary sewage discharge stage is complete, the plate is swiftly closed and the water outlet is then opened. Clean water enters the filter from the water inlet, arrives between the filter housing and the screen through the inside of the screen between the flap and the water inlet, and then reaches the inside of the screen through the screen between the flap and the water outlet. Meanwhile, under the conjunction of the fresh water and the returned water produced by the water outlet pipe, the sediment impurities are carried out of the filter, and the secondary sewage discharge is completed. Next, the flap and water outlet valve were reopened, and the sewage outlet valve was closed. If the pressure difference between the water inlet and outlet returns to the initial value of the pressure difference of the filter, the entire sewage discharge process is completed, and the system can begin the filtering cycle. Throughout the whole process, the water inlet pressure and the combined effect of the water inlet and returned water pressures are utilized in the two sewage discharge stages to clean the surface of the filter screen and move the sediment, respectively.

\section{Test devices and test methods of flap net filter}

\section{Test device}

In this experiment, a net filter for microirrigation with common specifications produced by Xinjiang Shihezi TianLu Water-Saving Equipment Co., Ltd. was used. The test device is shown in Figure 2. The test platform was built in the Engineering Hydraulics test hall of the School of Water Conservancy and Construction Engineering, Shihezi University, Xinjiang Uygur Autonomous Region, and prototype tests were used for all test work.

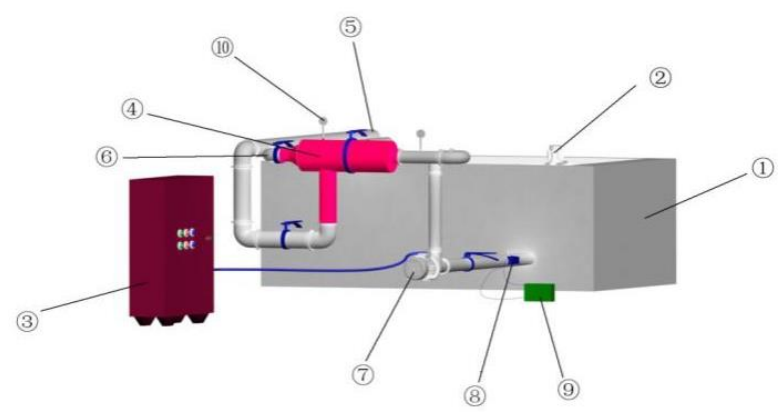

(1) Reservoir, (2) Sand settling mixing pool, (3) Frequency conversion cabinet, (4) Flap filter, (5) Water outlet pipe,

(6) Sewage outlet pipe, (7) Pump, (8) Water inlet pipe, (9) Flowmeter, (10) Manometer

FIGURE 2. Experimental device diagram.

\section{Test auxiliary facilities}

The auxiliary facilities used in this experiment are shown in Table 1.

TABLE 1. Supporting auxiliary facilities.

\begin{tabular}{cccc}
\hline Device & Model & Quantity & Specifications \\
\hline Water inlet pipe & & 1 & $200 \mathrm{~mm}$ \\
Water outlet pipe & & 1 & $200 \mathrm{~mm}$ \\
Sewage outlet pipe & & 1 & $150 \mathrm{~mm}$ \\
Three-phase asynchronous motor & Y90L-04 & 1 & Rated power $1.5 \mathrm{Kw}$ \\
Frequency conversion cabinet & DZB300B0015L4A & 1 & \\
Flowmeter & TDS-100P & 1 & Accuracy $0.001 \mathrm{~m}^{3} \mathrm{~s}^{-1}$ \\
Pressure Sensor & AS-131 & 4 & Accuracy $0.001 \mathrm{MPa}$ \\
Manometer & JDC600 & 3 & \\
Butterfly valve & & 3 &
\end{tabular}




\section{Test methods and steps}

The test device was installed and debugged according to Figure 2, and the orthogonal experimental method was used to arrange the experimental groups. In this experiment, the influent sediment concentration was set to five different values, i.e., $0.122 \mathrm{~g} \mathrm{~L}^{-1}, 0.234 \mathrm{~g} \mathrm{~L}^{-1}$, $0.278 \mathrm{~g} \mathrm{~L}^{-1}, 0.309 \mathrm{~g} \mathrm{~L}^{-1}$, and $0.336 \mathrm{~g} \mathrm{~L}^{-1}$, and the influent flow rate was set to six values, i.e., $140 \mathrm{~m}^{3} \mathrm{~h}^{-1}, 150 \mathrm{~m}^{3} \mathrm{~h}^{-1}$, $160 \mathrm{~m}^{3} \mathrm{~h}^{-1}, 170 \mathrm{~m}^{3} \mathrm{~h}^{-1}, 180 \mathrm{~m}^{3} \mathrm{~h}^{-1}$, and $200 \mathrm{~m}^{3} \mathrm{~h}^{-1}$. At the beginning of the experiment, artificially mixed river sand was added to the mixing tank. At the same time, water samples were taken at 8-min intervals from the water inlet of the water inlet pipe and the water outlet of the water outlet pipe until the end of the working cycle. When the plugging pressure difference of the filter reached its maximum value, the sewage discharge process started. During the first stage of the experiment, a sewage sample was taken at the sewage outlet. During the first sewage discharge stage, water samples were taken at 5-s intervals, and a total of 5 samples were taken. During the second sewage discharge stage, water samples were taken every $5 \mathrm{~s}$ until the end of the second stage. A total of 10 water samples could be taken during the second sewage discharge stage. Therefore, a total of 15 water samples could be obtained from both sewage discharge stages. Meanwhile, the filter inlet and outlet pressures were recorded simultaneously during the sewage discharge process. After the filtration and drainage tests were completed, the sand content of all water samples was measured, and all test work was completed. In this experiment, we used Excel 2010 and Origin 2018 for drawing and fitting the calculations. Two sets of experiments were performed under each working condition, and the average value of the two sets of experiments was taken as the statistical value under this working condition for analysis.

\section{Gradation of sand particles in the test}

Combining the characteristics of actual engineering applications and the analysis of sampling results, the filtered impurities from Xinjiang were mostly inert sediment impurities with a circular structure. In this test, the original riverbed sand from the Manas River Basin in Xinjiang, China, was used as the laboratory filtering sediment medium. The gradation of the particles was determined by sieving. Particles with a size of 0.1-1.52 mm accounted for $36 \%$ of the total sediment, and particles with a size of $0.01-0.1 \mathrm{~mm}$ accounted for $58 \%$ of the total sediment, which was in line with the actual project irrigation water sand particle gradation and can represent the characteristics of the actual project irrigation water source.

\section{Theoretical analysis of the drainage performance of the filter}

\section{Derivation of sewage discharge time equation}

The sewage discharge time is one of the important parameters for evaluating the sewage performance of the filter. Determining the sewage time accurately can reduce the impact of insufficient sewage time or excessive sewage time on the operation of the filter. Both stages of the sewage discharge process of the flap filter were theoretically analysed. The first sewage discharge stage was expressed as Stage $0-t_{1}$. In this stage, the cleaning of the screen between the water inlet and the flap is nearly completed. At this time, [eq. (1)] can be satisfied.

$$
S_{1}=S_{2}
$$

in which:

$S_{1}$ - sand content of the water sample at the inlet, $\mathrm{g} \mathrm{L}^{-1}$,

$S_{2}$ - sand content of the water sample at the sewage outlet, $\mathrm{g} \mathrm{L}^{-1}$.

The second sewage discharge stage was expressed as Stage $t_{1}-t_{2}$, in which the flap was closed; screen cleaning between the flap and the water outlet is largely completed in this stage, and all the remaining sediment is carried out of the filter. According to the mass conservation principle, [eq. (2)] can be satisfied.

$$
\mathrm{M}_{1}=\mathrm{M}_{2}
$$

in which:

$\mathrm{M}_{1}$ - the total amount of sand discharged from the sewage outlet, g,

$\mathrm{M}_{2}$ - the amount of sand blocked inside the filter, $\mathrm{g}$.

After the sewage discharge process is completed at $t_{2}$, if [eq. (1)] is satisfied, the whole sewage discharge process is considered to be complete.

The curves of sediment concentration and discharge time of the sewage outlet were analysed, and Origin software was used to fit the experimental results of multiple groups in the preliminary experiments. From the fitting results, it was found that the distribution curve approximated a normal distribution. Combined with the initial conditions, the relationship of mathematical expressions of the sewage sediment concentration and sewage discharge time can be expressed by [eq. (3)].

$$
\mathrm{S}_{2}=\mathrm{S}_{1}+A \exp \left(-\frac{(\mathrm{t}-\mu)^{2}}{2 \sigma^{2}}\right)
$$

in which:

$$
\begin{aligned}
& \sigma \text { - the standard deviation; } \\
& \mu \text { - the expected value; } \\
& A \text { - the flow correction coefficient, } \\
& \mathrm{t} \text { - the total sewage discharge time, s. }
\end{aligned}
$$

In [eq. (3)], when $S_{1}=S_{2}$, the filter process was considered completed, and then the system entered the next filtering cycle.

\section{Derivation of pressure difference variation equation}

According to the mass conservation principle, the total amount of sand clogged in the screen during the entire filtering process can be calculated using [eq. (4)]. 


$$
M_{2}=\Delta \mathrm{S} Q_{1} \mathrm{~T}
$$

in which:

$\Delta S$ - the difference in the sand content between the inlet and outlet, $\mathrm{g} \mathrm{L}^{-1}$;

$Q_{1}$ - the influent flow rate, $\mathrm{m}^{3} \mathrm{~h}^{-1}$,

$\mathrm{T}$ - the filtration time, $\mathrm{s}$.

According to the study on the flow and sand force of the pressure irrigation pipe by Zhongchao Liu (Liu, 1991), the flow and sand force of the pressure irrigation pipe can be calculated using [eq. (5)].

$$
S_{*}=\frac{\lambda v^{2}}{0.000023 \omega^{0.25 .8 g}}
$$

in which:

$S_{*}$ - the sand flow force of the pressure irrigation pipeline, $\mathrm{g} \mathrm{L}^{-1}$;

$v$ - the average flow rate in the pipeline, $\mathrm{m} \mathrm{s}^{-1}$;

$g$ - the acceleration of gravity, $\mathrm{m} \mathrm{s}^{-2}$;

$\omega$ - the average sedimentation speed of the sediment, $\mathrm{mm} \mathrm{s}^{-1}$,

$\lambda$ - the resistance coefficient along the pipeline.

The filter was made of steel pipe or cast iron material, and the resistance coefficient along the pipeline can be calculated using [eq. (6)].

$$
\lambda=\frac{0.02164}{d^{0.1}}
$$

in which:

\section{$d$ - the diameter of the pipe, $\mathrm{m}$.}

The discharge process of the flap filter included two stages. The first sewage discharge mainly completes the cleaning of the screen between the water inlet and the flap. In this stage, the pressure change can be expressed by [eq. (7)].

$$
\Delta P_{1}=\beta\left(M_{2}-S_{*} Q_{2} T_{1}\right)
$$

in which:

$\Delta \mathrm{P}_{1}$ - the pressure difference change in the first discharge stage, $\mathrm{m}$;

$Q_{2}$ - the discharge flow rate, $\mathrm{m}^{3} \mathrm{~h}^{-1}$;

$T_{1}$ - the discharge time of the first stage, $\mathrm{s}$,

$\beta$ - the adjustment coefficient for the pressure difference, $\mathrm{m} \mathrm{kg}^{-1}$ (in this study, $\beta$ was set to 0.6 ).

The secondary drainage mainly completes the cleaning of the screen between the flap and the water outlet, and all the remaining sediment is carried out of the filter. The pressure change can be expressed by [eq. (8)].

$$
\Delta P_{2}=\beta\left((1-\gamma) M_{2}-S_{*} Q_{2} T_{2}\right)
$$

in which:

$\Delta \mathrm{P}_{2}$ - the variation of pressure difference in the secondary discharge stage, $\mathrm{m}$;

$T_{2}$ - the discharge time in the secondary stage, $\mathrm{s}$,

$\gamma$ - the percentage of completed sewage.

(The primary discharge mainly completes the transport of sediment. Combined with the statistics of the measurement results of the sand content of the water sample at the discharge port in several groups of pretests, the sand discharge at the discharge port of the primary stage is $10 \%$ of the total amount of sand blocked inside the screen, so $\gamma$ is set to $10 \%$ for the flap filter).

After both discharge stages were completed, the flap was reopened. When the sum of the pressure difference between the two discharge stages is close to the total head loss in the filtration process, as shown in [eq. (9)], the discharge process can be considered to be complete, and the system can enter the next filtering cycle.

$$
\Delta \mathrm{P}=\Delta P_{1}+\Delta P_{2}=\Delta H
$$

in which:

$\Delta P$ - the sum of the sewage pressure difference in both stages, $\mathrm{m}$,

$\Delta H$ - the total head loss, $\mathrm{m}$.

\section{Derivation of sewage performance equation}

After the sewage is discharged, filter cleanliness is another important parameter to evaluate the sewage performance of the filter. Cleanliness directly determines the operation status of the next working cycle. After discharge through the filter screen, cleanliness is defined as the ratio of the total amount of discharged sand at the sewage outlet to the amount of sand clogged inside the filter. The cleanliness of the filter $\varphi$ can be expressed by [eq. (10)].

$$
\varphi=\frac{M_{1}}{M_{2}}
$$

(1) Calculation of the amount of sand clogged inside the filter screen

According to the mass conservation principle, the amount of sand blocked in the filter was calculated by the difference between the total amount of sand at the water inlet and the total amount of sand at the water outlet, as shown in [eq. (4)].

(2) Calculation of the total amount of sediment discharged from the sewage outlet

Equation (11) can be obtained by integrating [eq. (3)].

$$
\mathrm{M}_{1}=\mathrm{Q}_{2} \int_{0}^{\mathrm{t}} \mathrm{s}_{2} \mathrm{dt}
$$

There is no analytical solution to the integral of the normal distribution. Qingyi Liu (Liu et al. 2009) gave an approximate calculation formula for the integral of the normal distribution, as shown in Equation (12). 


$$
\mathrm{F}_{\mathrm{t}}=\frac{\exp (\mathrm{a}(\mathrm{t}-\mu))}{1+\exp (\mathrm{a}(\mathrm{t}-\mu))}, \mathrm{a}=\frac{4}{\sqrt{2 \pi} \sigma}
$$

By combining eqs (3), (11) and (12), the mathematical expression for the total amount of sediment discharged from the sewage outlet can be obtained, as shown in [eq. (13)].

$$
M_{1}=Q_{2} S_{1} t+Q_{2} \sqrt{2 \pi} \sigma A \frac{\exp (a(t-\mu))}{1+\exp (a(t-\mu))}, a=\frac{4}{\sqrt{2 \pi} \sigma}
$$

From eqs (4), (10) and (13), the cleanliness $\varphi$ can be calculated by [eq. (14)].

$$
\varphi=\frac{\mathrm{Q}_{2} \mathrm{~S}_{1} \mathrm{t}+\mathrm{Q}_{2} \sqrt{2 \pi} \sigma \mathrm{A} \frac{\exp (\mathrm{a}(\mathrm{t}-\mu))}{1+\exp (\mathrm{a}(\mathrm{t}-\mu))}}{\Delta \mathrm{SQ}_{1} \mathrm{~T}}, \mathrm{a}=\frac{4}{\sqrt{2 \pi} \sigma}
$$
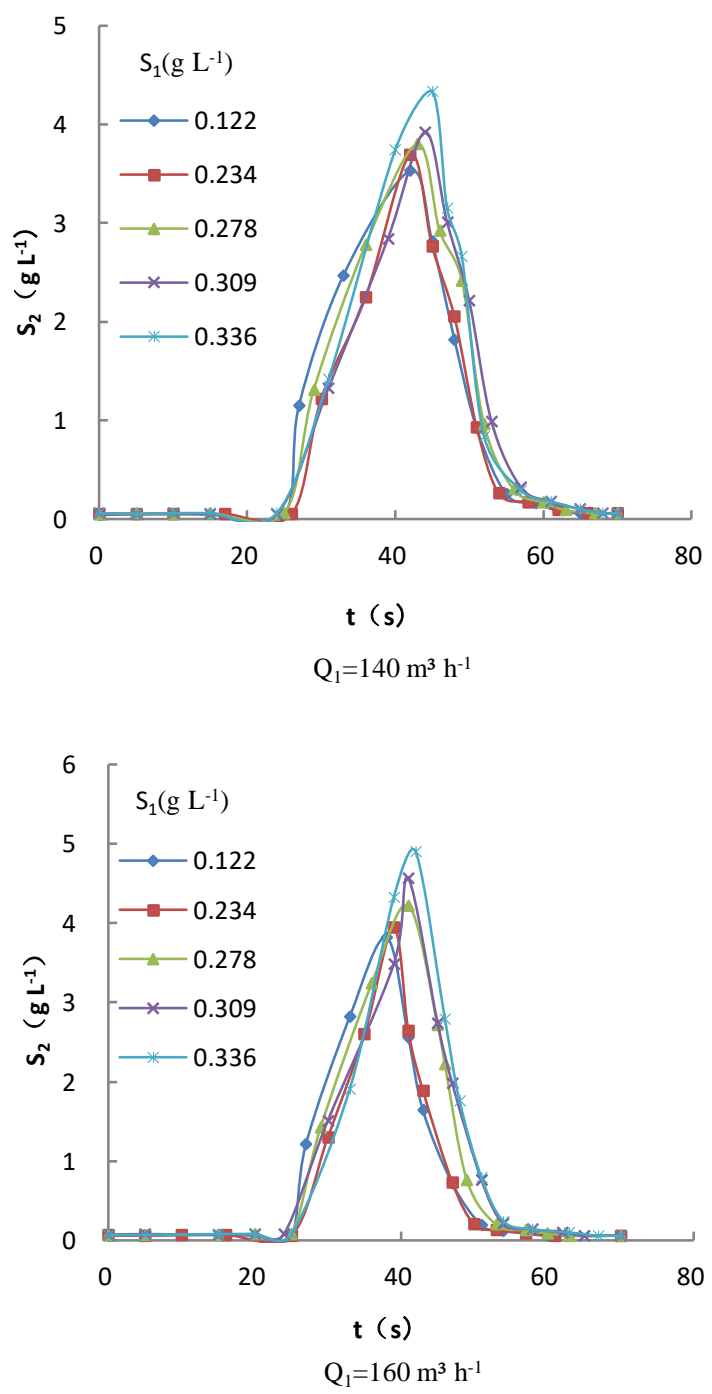

\section{RESULTS AND DISCUSSION}

A sewage discharge performance test of an 80-mesh rectangular filter commonly used in field microirrigation was performed. Before the formal experiment began, multiple groups of preliminary experiments were conducted to determine the sewage discharge flow rate. In the sewage discharge experiment, the flow rate was set to a commonly used value in field irrigation projects, i.e., $180 \mathrm{~m}^{3} \mathrm{~h}^{-1}$. The sewage discharge time of the first stage was $25 \mathrm{~s}$, and the sewage discharge time of the second stage was $50 \mathrm{~s}$. Under 6 different outlet flow rates, the sand content of the water sample was measured at the sewage outlet, and the trends of water sample sediment concentrations were obtained, as shown in Figure 3. The trends of the filter inlet and outlet pressure difference $\mathrm{P}$ with time under 6 different flow rates were also obtained, as shown in Figure 4.

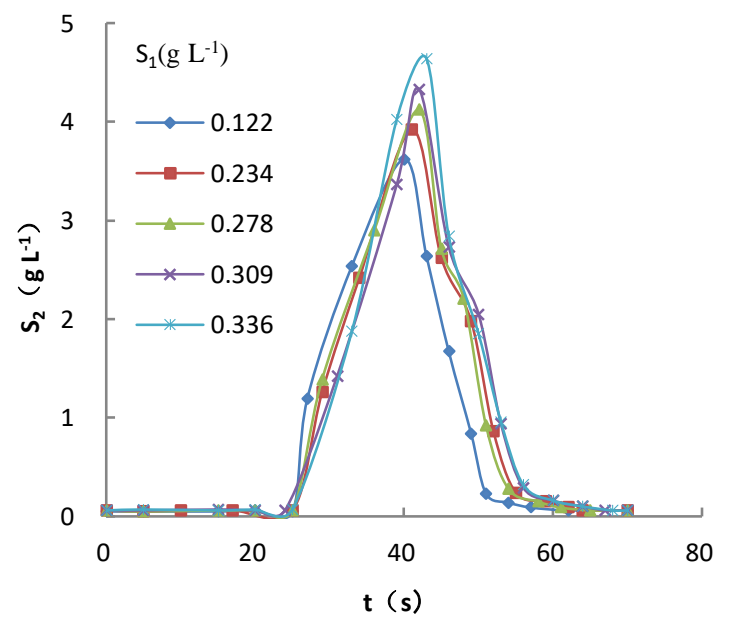

$\mathrm{Q}_{1}=150 \mathrm{~m}^{3} \mathrm{~h}^{-1}$

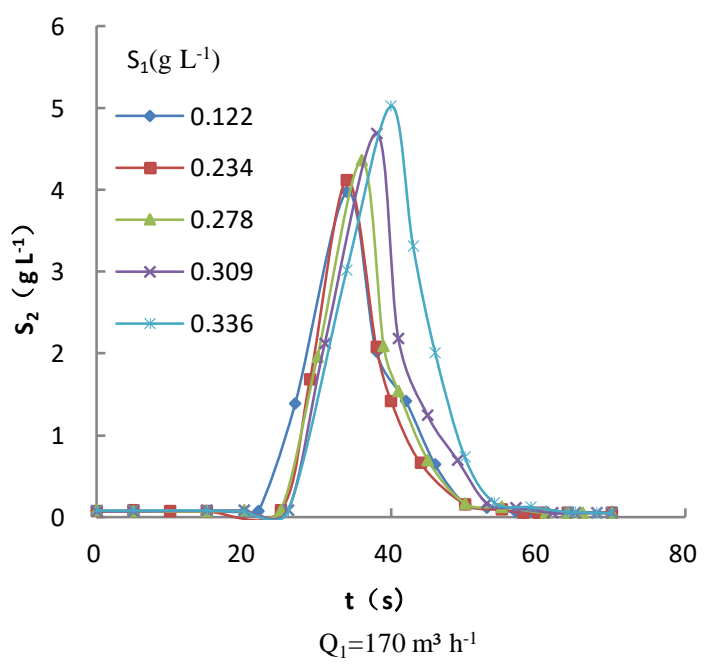



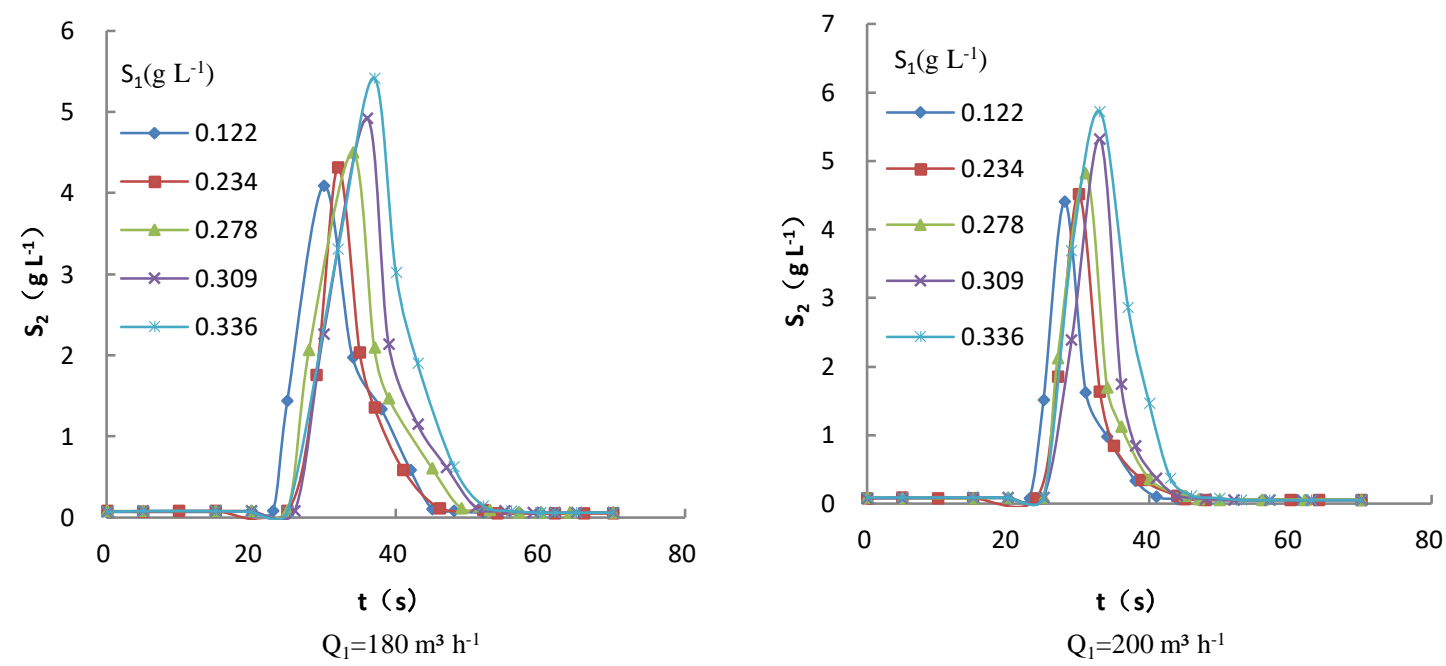

FIGURE 3. Trend of sediment content of sewage outlet over time.
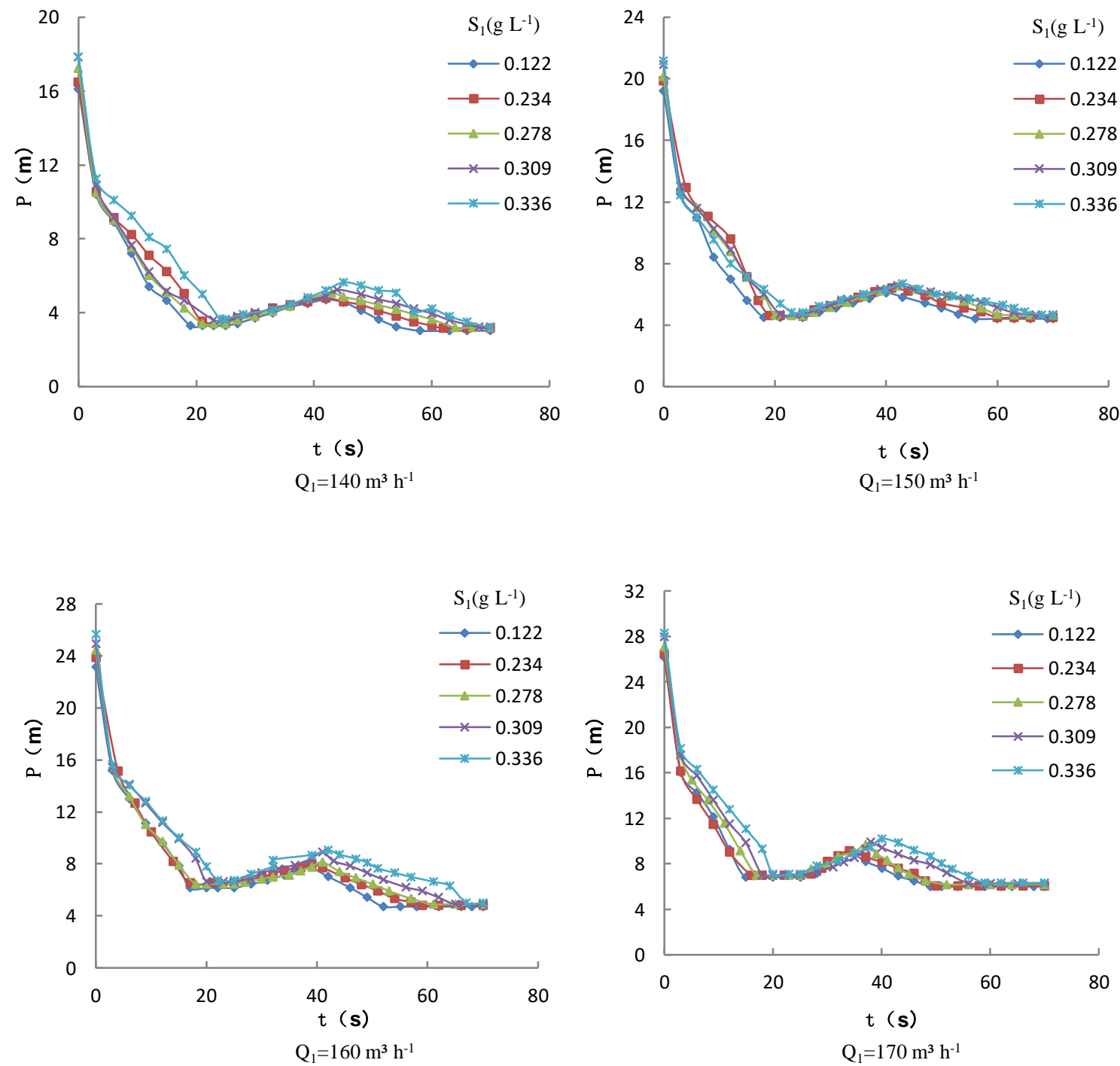

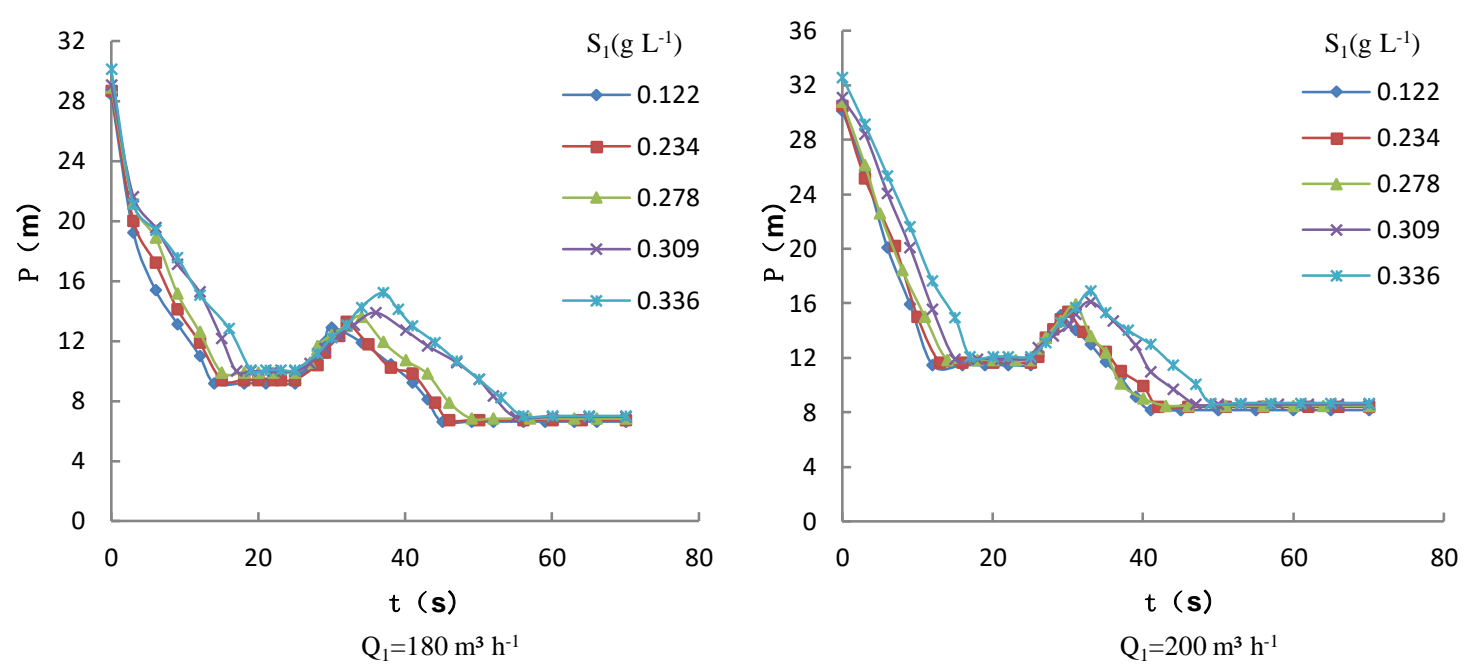

FIGURE 4. Trend of inlet and outlet pressure difference over time.

\section{Analysis of experimental results}

\section{(1) Sewage discharge time analysis}

Through orthogonal experimental analysis, when the influent flow rate was constant, the sediment concentration of the water only exhibited a small effect on the discharge time. The influent sediment concentration mainly affected the peak content of the sediment, and the influent flow rate was the main factor affecting the filter discharge time. The curves of the sand content at the sewage outlet versus the sewage discharge time were analysed at the inlet flow rate in the range of $140-200 \mathrm{~m}^{3} \mathrm{~h}^{-1}$. The analysis results indicated that the sand content at the sewage outlet had a certain variation pattern with the sewage discharge time. During the first sewage discharge stage, the sediment impurities between the water inlet and the flap were mostly moved to the vicinity of the discharge outlet. Therefore, during the first $0-25 \mathrm{~s}$, the filter operated in the first sewage discharge stage, and the sand content at the discharge outlet was maintained constant, which was basically equal to the sand content of the sewage water. After $25 \mathrm{~s}$, the filter operated in the second discharge stage. The sand content at the sewage outlet quickly increased to the peak and then gradually decreased to the sand content of sediment water and remained unchanged.

The results in Figure 3 reveal that when the inlet water flow rate was constant, the time to the peak sediment concentration at the sewage outlet and the total sewage discharge time increased with increasing inlet sediment concentrations. However, both time parameters were altered by less than $1.5 \mathrm{~s}$. When the amount of sand was constant, the time to the peak sand amount at the sewage outlet and the total sewage discharge time decreased with increasing water flow rates. When the inlet water flow was controlled under $160 \mathrm{~m}^{3} \mathrm{~h}^{-1}$, the time to reach the peak discharge was $40-45 \mathrm{~s}$, and the total discharge time was 63-69 s. When the inlet water flow rate was controlled to be greater than $160 \mathrm{~m}^{3} \mathrm{~h}^{-1}$, the discharge reached the peak value at $30-40 \mathrm{~s}$, and the total sewage discharge time was $48-53 \mathrm{~s}$. The experimental results under various flow conditions were fitted using Origin software, and then the experimental data were compared with the fitted results. The comparison results are shown in Table 2. 
TABLE 2. Fitting calculation table of sewage discharge time.

\begin{tabular}{|c|c|c|c|c|c|c|}
\hline$S_{1}\left(g^{-1}\right)$ & $Q_{1}\left(m^{3} h^{-1}\right)$ & $\mathbf{t}_{1}(\mathbf{s})$ & $t_{2}(s)$ & Error(s) & Error percentages & Fit degree \\
\hline \multirow{6}{*}{0.122} & 140 & 65.56 & 65 & 0.56 & $0.85 \%$ & \multirow{6}{*}{0.96} \\
\hline & 150 & 61.28 & 62 & -0.72 & $-1.17 \%$ & \\
\hline & 160 & 57.63 & 60 & -2.37 & $-4.11 \%$ & \\
\hline & 170 & 52.32 & 50 & 2.32 & $4.43 \%$ & \\
\hline & 180 & 43.91 & 45 & -1.09 & $-2.48 \%$ & \\
\hline & 200 & 36.18 & 39 & -2.82 & $-7.79 \%$ & \\
\hline \multirow{6}{*}{0.234} & 140 & 66.21 & 66 & 0.21 & $0.32 \%$ & \multirow{6}{*}{0.97} \\
\hline & 150 & 67.85 & 64 & 3.85 & $5.67 \%$ & \\
\hline & 160 & 58.39 & 61 & -2.61 & $-4.47 \%$ & \\
\hline & 170 & 49.26 & 51 & -1.74 & $-3.53 \%$ & \\
\hline & 180 & 42.68 & 46 & -3.32 & $-7.78 \%$ & \\
\hline & 200 & 38.96 & 42 & -3.04 & $-7.80 \%$ & \\
\hline \multirow{6}{*}{0.278} & 140 & 65.31 & 67 & -1.69 & $-2.59 \%$ & \multirow{6}{*}{0.97} \\
\hline & 150 & 62.59 & 65 & -2.41 & $-3.85 \%$ & \\
\hline & 160 & 60.52 & 63 & -2.48 & $-4.10 \%$ & \\
\hline & 170 & 47.79 & 52 & -4.21 & $-8.81 \%$ & \\
\hline & 180 & 44.91 & 49 & -4.09 & $-9.11 \%$ & \\
\hline & 200 & 39.31 & 43 & -3.69 & $-9.39 \%$ & \\
\hline \multirow{6}{*}{0.309} & 140 & 68.91 & 68 & 0.91 & $1.32 \%$ & \multirow{6}{*}{0.97} \\
\hline & 150 & 69.3 & 67 & 2.30 & $3.32 \%$ & \\
\hline & 160 & 65.88 & 65 & 0.88 & $1.34 \%$ & \\
\hline & 170 & 52.96 & 54 & -1.04 & $-1.96 \%$ & \\
\hline & 180 & 48.64 & 51 & -2.36 & $-4.85 \%$ & \\
\hline & 200 & 42.64 & 44 & -1.36 & $-3.19 \%$ & \\
\hline \multirow{6}{*}{0.336} & 140 & 66.58 & 68 & -1.42 & $-2.13 \%$ & \multirow{6}{*}{0.98} \\
\hline & 150 & 65 & 68 & -3.00 & $-4.62 \%$ & \\
\hline & 160 & 60.44 & 66 & -5.56 & $-9.20 \%$ & \\
\hline & 170 & 57.55 & 60 & -2.45 & $-4.26 \%$ & \\
\hline & 180 & 54.52 & 58 & -3.48 & $-6.38 \%$ & \\
\hline & 200 & 47.35 & 49 & -1.65 & $-3.48 \%$ & \\
\hline
\end{tabular}

Table 2 shows that under each flow condition, the maximum error between the fitted result $t_{1}$ and the experimental result $t_{2}$ is $3.85 \mathrm{~s}$, the error percentages are less than $10 \%$, and the fit degree can reach higher than 96\%. Combining experimental data and engineering situations, when the inflow water flow rate is lower than $160 \mathrm{~m}^{3} \mathrm{~h}^{-1}$, the total discharge time from both the calculation and the experimental results is in the range of $60-70 \mathrm{~s}$. Thus, when the inflow water flow is lower than $160 \mathrm{~m}^{3} \mathrm{~h}^{-1}$, the discharge time should be set to $70 \mathrm{~s}$. When the inflow water flow rate is higher than $160 \mathrm{~m}^{3}$ $\mathrm{h}^{-1}$, the total discharge time from both the calculation and the experimental results is in the range of 40-50 s. Therefore, when the inflow water flow rate is higher than $160 \mathrm{~m}^{3} \mathrm{~h}^{-1}$, the sewage time should be set to $50 \mathrm{~s}$. At these settings, both the problems, i.e., excessive water consumption due to excessive sewage discharge time and substandard cleaning effect due to insufficient sewage discharge time, can be avoided.

\section{(2) Analysis of sewage pressure difference}

Based on the orthogonal test analysis, the discharge pressure difference exhibited a consistent variation pattern with the discharge time under all flow conditions. When the discharge flow rate was controlled to be constant, during the first discharge process, the initial pressure difference was equal to the peak water head loss during the filter process, which indicated that at a higher filtration flow rate, the initial pressure difference was greater and the first discharge was completed earlier. When the inlet flow rate was less than $160 \mathrm{~m}^{3} \mathrm{~h}^{-1}$, it took 17-24 $\mathrm{s}$ for the first-stage discharge pressure difference to reach a stable value. When the inlet flow rate was greater than $160 \mathrm{~m}^{3} \mathrm{~h}^{-1}$, it took $12-24 \mathrm{~s}$ for the first-stage discharge pressure to reach a stable value. In the second discharge stage, when the flap was completely closed, the pressure difference reached its peak again and entered the second discharge. From the analysis in Figure 4 , it can be found that as the filtration flow rate increased, the peak sediment content at the sewage outlet increased, 
and the time to reach the peak decreased. When the inlet water flow rate was lower than $160 \mathrm{~m}^{3} \mathrm{~h}^{-1}$, it took 14-25 $\mathrm{s}$ for the second-stage discharge pressure difference to reach a stable value. When the inlet water flow rate was higher than $160 \mathrm{~m}^{3} \mathrm{~h}^{-1}$, the required time for the second-stage pressure difference to reach stability was 12-19 s. The test results under working conditions with flow rates of $170 \mathrm{~m}^{3} \mathrm{~h}^{-1}, 180 \mathrm{~m}^{3} \mathrm{~h}^{-1}$ and $200 \mathrm{~m}^{3} \mathrm{~h}^{-1}$ and different inflow sand contents were fitted, and then the fitted results were compared with the test results. The comparison of the calculation results and test results for the discharge pressure difference and the discharge time at flow rates of $170 \mathrm{~m}^{3} \mathrm{~h}^{-1}, 180 \mathrm{~m}^{3} \mathrm{~h}^{-1}$ and $200 \mathrm{~m}^{3} \mathrm{~h}^{-1}$ are shown in Table 3, Table 4 and Table 5, respectively.

TABLE 3. Comparison of the calculation results and test results for the discharge pressure difference and the discharge time at flow rates of $170 \mathrm{~m}^{3} \mathrm{~h}^{-1}$.

\begin{tabular}{|c|c|c|c|c|c|c|c|c|c|}
\hline $\begin{array}{c}\mathrm{S}_{1} \\
\left(\mathrm{~g} \mathrm{~L}^{-1}\right)\end{array}$ & $\begin{array}{c}\mathbf{T} \\
\text { (s) } \\
\end{array}$ & $\begin{array}{l}\Delta \mathbf{H} \\
(\mathbf{m})\end{array}$ & $\begin{array}{l}\mathbf{T}_{1} \\
\text { (s) } \\
\end{array}$ & $\begin{array}{l}\Delta \mathbf{P}_{1} \\
(\mathbf{m})\end{array}$ & $\begin{array}{l}\mathbf{T}_{2} \\
\text { (s) }\end{array}$ & $\begin{array}{l}\Delta \mathbf{P}_{2} \\
(\mathbf{m})\end{array}$ & $\begin{array}{l}\Delta \mathbf{P} \\
(\mathbf{m})\end{array}$ & Error percentages & Fit degree \\
\hline 0.122 & 2930 & 26.11 & 11 & 12.07 & 12 & 17.79 & 29.86 & $9.21 \%$ & \multirow{4}{*}{$96.25 \%$} \\
\hline 0.234 & 1890 & 26.43 & 14 & 11.3 & 14 & 16.75 & 28.05 & $5.76 \%$ & \\
\hline 0.278 & 1678 & 26.81 & 16 & 11.81 & 15 & 17.63 & 29.44 & $8.93 \%$ & \\
\hline 0.309 & 1501 & 27.02 & 16 & 11.73 & 15 & 17.51 & 29.24 & $7.62 \%$ & \\
\hline
\end{tabular}

TABLE 4. Comparison of the calculation results and test results for the discharge pressure difference and the discharge time at flow rates of $180 \mathrm{~m}^{3} \mathrm{~h}^{-1}$.

\begin{tabular}{cccccccccc}
\hline $\begin{array}{c}\mathbf{S}_{1} \\
\left(\mathbf{g ~ L}^{\mathbf{1}}\right)\end{array}$ & $\begin{array}{c}\mathbf{T} \\
(\mathbf{s})\end{array}$ & $\begin{array}{c}\Delta \mathbf{H} \\
(\mathbf{m})\end{array}$ & $\begin{array}{c}\mathbf{T}_{1} \\
(\mathbf{s})\end{array}$ & $\begin{array}{c}\Delta \mathbf{P}_{1} \\
(\mathbf{m})\end{array}$ & $\begin{array}{c}\mathbf{T}_{2} \\
(\mathbf{s})\end{array}$ & $\begin{array}{c}\Delta \mathbf{P}_{2} \\
(\mathbf{m})\end{array}$ & $\begin{array}{c}\Delta \mathbf{P} \\
(\mathbf{m})\end{array}$ & Error percentages & Fit degree \\
\hline $\mathbf{0 . 1 2 2}$ & 2712 & 28.43 & 10 & 11.89 & 12 & 17.40 & 29.29 & $3.02 \%$ & \\
$\mathbf{0 . 2 3 4}$ & 1912 & 28.96 & 15 & 12.10 & 14 & 18.08 & 30.18 & $4.21 \%$ & $98.67 \%$ \\
$\mathbf{0 . 2 7 8}$ & 1622 & 29.00 & 16 & 12.12 & 15 & 18.09 & 30.21 & $4.17 \%$ & \\
$\mathbf{0 . 3 0 9}$ & 1460 & 29.08 & 16 & 12.13 & 17 & 17.81 & 29.94 & $2.96 \%$ & \\
\hline
\end{tabular}

TABLE 5. Comparison of the calculation results and test results for the discharge pressure difference and the discharge time at flow rates of $200 \mathrm{~m}^{3} \mathrm{~h}^{-1}$.

\begin{tabular}{|c|c|c|c|c|c|c|c|c|c|}
\hline $\begin{array}{c}S_{1} \\
\left(\mathrm{~g} \mathrm{~L}^{-1}\right)\end{array}$ & $\begin{array}{c}\mathbf{T} \\
(\mathbf{s}) \\
\end{array}$ & $\begin{array}{l}\Delta \mathbf{H} \\
(\mathbf{m})\end{array}$ & $\begin{array}{l}\mathbf{T}_{1} \\
(\mathrm{~s}) \\
\end{array}$ & $\begin{array}{l}\Delta \mathbf{P}_{1} \\
(\mathbf{m})\end{array}$ & $\begin{array}{l}\mathbf{T}_{2} \\
(\mathbf{s}) \\
\end{array}$ & $\begin{array}{l}\Delta \mathbf{P}_{2} \\
(\mathbf{m})\end{array}$ & $\begin{array}{l}\Delta \mathbf{P} \\
(\mathbf{m}) \\
\end{array}$ & Error percentages & Fit degree \\
\hline 0.122 & 2641 & 30.32 & 12 & 12.77 & 12 & 18.97 & 31.74 & $4.68 \%$ & \multirow{4}{*}{$97.41 \%$} \\
\hline 0.234 & 1803 & 30.46 & 16 & 12.66 & 15 & 18.90 & 31.56 & $3.61 \%$ & \\
\hline 0.278 & 1520 & 30.78 & 16 & 12.68 & 17 & 18.64 & 31.32 & $1.75 \%$ & \\
\hline 0.309 & 1375 & 31.08 & 17 & 12.67 & 19 & 18.46 & 31.13 & $0.16 \%$ & \\
\hline
\end{tabular}

At an inlet flow rate of $170 \mathrm{~m}^{3} \mathrm{~h}^{-1}$, the experimental results were compared with the fitted results. The discrepancy in the change in the total pressure difference between the experimental results and the calculated results was less than $3 \mathrm{~m}$, and the discrepancy in the pressure difference was less than $10 \%$. The fit degree of the formula was up to above $96 \%$. At an inlet flow of $180 \mathrm{~m}^{3} \mathrm{~h}^{-1}$, the error of the total pressure difference change between the experimental results and the calculated results was less than $1.2 \mathrm{~m}$, and the error in the pressure difference was less than $5 \%$. Thus, the formula had a fit degree of higher than $98 \%$. At a water flow rate of $200 \mathrm{~m}^{3} \mathrm{~h}^{-1}$, the error in the total pressure difference between the experimental results and the calculated results was less than $1.5 \mathrm{~m}$, and the error in the pressure difference was less than $5 \%$. The fit degree of the formula could reach above $97 \%$. In a practical irrigation system, the working flow rate of the flap-type mesh filter was in the range of $180-220 \mathrm{~m}^{3} \mathrm{~h}^{-1}$. Based on the experimental results and calculation results, when the field flow rate of the flap-type mesh filter was between $180 \mathrm{~m}^{3} \mathrm{~h}^{-1}$ and $200 \mathrm{~m}^{3} \mathrm{~h}^{-1}$, the first discharge of the flap filter lasted for $20 \mathrm{~s}$, the second discharge lasted for $20 \mathrm{~s}$, and the total discharge time was $40 \mathrm{~s}$. In addition, in the second discharge stage, it took time for the solenoid valve to turn the flap off. According to the experimental measurement, at a flow rate of $180 \mathrm{~m}^{3} \mathrm{~h}^{-1}$, it took 8-10 s to completely close the flap. Therefore, the total sewage discharge time should be set to $50 \mathrm{~s}$. The sewage discharge time of the flap filter can be accurately determined under actual working conditions, which can ensure the best sewage discharge effect.

\section{(3) Sewage discharge effect analysis}

Based on orthogonal experimental analysis, the filter drainage cleanliness was mainly affected by the 
inlet water flow rate of the filter. When the flow rate of the sewage discharge was $180 \mathrm{~m}^{3} \mathrm{~h}^{-1}$, the amount of clogged sand inside the filter and the total amount of sand discharged from the sewage outlet were measured under different inlet water flow rates in the range of $150-200 \mathrm{~m}^{3} \mathrm{~h}^{-1}$. The results are shown in Table 6 .

TABLE 6. Summary of calculation results for sewage cleanliness.

\begin{tabular}{|c|c|c|c|c|c|c|c|c|c|c|c|c|c|c|c|}
\hline$Q_{1}\left(m^{3} h^{-1}\right)$ & & 150 & & & 160 & & & 170 & & & 180 & & & 200 & \\
\hline $\mathrm{S}_{1}(\mathrm{~g} \mathbf{I}$ & $\begin{array}{l}\mathrm{M}_{2} \\
(\mathrm{~kg})\end{array}$ & $\begin{array}{c}\mathrm{M}_{1} \\
(\mathrm{~kg})\end{array}$ & $\varphi$ & $\begin{array}{l}\mathrm{M}_{2} \\
(\mathrm{~kg})\end{array}$ & $\begin{array}{l}\mathrm{M}_{1} \\
(\mathrm{~kg})\end{array}$ & $\varphi$ & $\begin{array}{c}\mathrm{M}_{2} \\
(\mathrm{~kg})\end{array}$ & $\begin{array}{l}\mathrm{M}_{1} \\
(\mathrm{~kg})\end{array}$ & $\varphi$ & $\begin{array}{l}\mathrm{M}_{2} \\
(\mathrm{~kg})\end{array}$ & $\begin{array}{l}\mathrm{M}_{1} \\
(\mathrm{~kg})\end{array}$ & $\varphi$ & $\begin{array}{l}\mathrm{M}_{2} \\
(\mathrm{~kg})\end{array}$ & $\begin{array}{l}\mathrm{M}_{1} \\
(\mathrm{~kg})\end{array}$ & $\varphi$ \\
\hline 0.122 & .12 & 2.39 & 0.88 & 2.35 & 2.21 & 0.94 & 2.04 & 2.02 & 0.99 & 2 & 1.96 & 0.98 & 1.56 & 1.52 & 0.97 \\
\hline 0.234 & 3.66 & 3.53 & 0.96 & 2.94 & 2.78 & 0.95 & 2.61 & 2.43 & 0.93 & 2.03 & 1.99 & 0.98 & 1.78 & 1.65 & 0.93 \\
\hline 0.278 & 4.74 & 4.04 & 0.85 & 3.93 & 3.91 & 0.99 & 3.06 & 2.76 & 0.90 & 2.78 & 2.71 & 0.97 & 2.42 & 2.35 & 0.97 \\
\hline 0.309 & 4.44 & 4.39 & 0.99 & 4.33 & 4.24 & 0.98 & 3.49 & 3.23 & 0.93 & 2.99 & 2.94 & 0.98 & 2.57 & 2.35 & 0.91 \\
\hline 0.336 & 6.86 & 4.63 & 0.67 & 6.77 & 4.27 & 0.63 & 4.51 & 4.13 & 0.92 & 4.62 & 4.55 & 0.98 & 3.77 & 3.55 & 0.94 \\
\hline
\end{tabular}

Table 6 shows that when the sediment content is constant, the cleanliness of the sewage discharge is linearly dependent on the inflow water flow. When the inlet water flow rate was lower than $160 \mathrm{~m}^{3} \mathrm{~h}^{-1}$, the cleanliness of the sewage was below $90 \%$. At smaller flow rates, the cleanliness was worse. When the inlet water flow rate was higher than $160 \mathrm{~m}^{3} \mathrm{~h}^{-1}$, the cleanliness of the sewage was a constant value greater than $90 \%$. Thus, as the inlet water flow rate increased, the sewage cleanliness $\varphi$ increased accordingly. At a constant inlet water flow rate, when the sand content varied, the change in the cleanliness of the sewage was small. Thus, the effect of the sand content on the cleanliness was insignificant. At the same time, it was found that when the flow rate was $180 \mathrm{~m}^{3} \mathrm{~h}^{-1}$, the cleanliness was basically stable above $97 \%$; that is, when the flow rate was high, the influent water flow rate was the main factor influencing the cleanliness, and the sand content had much less influence on cleanliness than water flow. Therefore, to ensure a high degree of filter cleanliness, it is recommended to run the filter at an appropriately increased flow rate, which can ensure good operating conditions in the next filtration cycle.

\section{(4) Energy consumption analysis}

The new flap-type mesh filter mainly utilizes the pressure difference between the inside and outside of the filter to complete the drainage work. In the sewage discharge process, there is no need to drive an additional motor to clean and discharge the sewage, which avoids power losses during the sewage discharge process. The sewage discharge process was studied under two conditions, i.e., a long time with a low flow rate and a short time with a high flow rate. The flow-time method was used to calculate the water consumption in the sewage discharge process. By analysing the experimental group with the maximum sand content in Table 2, the water consumption value during sewage discharge was calculated to be $2.64 \mathrm{~m}^{3}, 2.76 \mathrm{~m}^{3}, 2.89 \mathrm{~m}^{3}, 2.55 \mathrm{~m}^{3}, 2.55$ $\mathrm{m}^{3}$, and $2.44 \mathrm{~m}^{3}$ at each flow rate. At all flow rates, the water consumption values were less than $3.0 \mathrm{~m}^{3}$, which meets the requirements for water conservation in irrigation projects. Therefore, it is reasonable to set the sewage discharge flow rate to $180 \mathrm{~m}^{3} \mathrm{~h}^{-1}$.

Investigating the drainage time and drainage effect of the mesh filter can guide the determination of the optimal drainage time of the mesh filter. In this study, it was revealed that the factors affecting the sewage discharge process of the flap filter included the influent flow rate and the influent sand content, and the influent flow rate was the main influencing factor. The sewage discharge stage mainly completed the discharge of the clogged impurities inside the filter. Under the same flow conditions, the flap filter reached the same peak water head loss (Shi et al. 2020; Liu et al. 2019 ; Zong et al. 2015; Puig-Bargués et al. 2005; Yurdem et al. 2010). The total amount of impurities blocked inside the filter is the total amount of impurities flowing into the filter screen under the working conditions of flow rate $\mathrm{Q}$ and sand content $\mathrm{S}$ at time $\mathrm{t}$. Under different flow rates and inlet water sand contents, the total amount of internal clogging debris mass was basically the same. Combined with the analysis of the principle of mass conservation, when discharging, the total amount of impurities discharged inside the filter was proportional to the discharge water flow, the amount of sand in the water and the discharge time, and the influence of the water flow on the total amount of impurities inside the filter was much greater than the amount of sand in the water. Therefore, the influence of the influent flow rate on the discharge process was greater than the influence of the influent sand content. This result was consistent with the research results of the relevant experts in the study of mesh filters (Zong et al. 2019; Song, 2017; Li et al. 2014). Combining the analysis of the principle of mass conservation and the principle of sediment carrying in water flow, under the same working conditions, the larger the influent flow is, the stronger the sediment carrying capacity, the shorter the sewage discharge time, and the better the filter cleaning effect. This study suggested a high influent flow rate for a given discharge. Through the experiments, when the influent flow rate was $180 \mathrm{~m}^{3} \mathrm{~h}^{-1}$, the sewage discharge time was determined to be $50 \mathrm{~s}$, which can achieve a good sewage 
discharge effect without affecting the next filtration cycle. This result was consistent with the study results of other related experts on the discharge time of the filter ( $\mathrm{Li}$ et al. 2019; Song, 2017; Li et al. 2014). Discharge water consumption is one of the important indicators used to analyse the performance of sewage discharge. Under the same sand content in inlet water, when the total discharge time is set to the point of constant sand content and constant discharge pressure difference at the discharge port, the discharge water consumption is basically the same regardless of whether using a low flow rate for a long time or a high flow rate for a short time. Mesh filter preblocking is mainly employed to complete the clogging of the filter mesh. After clogging the filter mesh, the surface of the filter will be blocked to accumulate a filter cake layer. If the drainage flow rate is small and the sand carrying capacity is poor, the mesh filter with the direct flushing principle can only prolong the discharge time and cannot achieve the cleaning effect; instead, the water consumption in the discharge process is increased. The high inlet flow rate had a large sand-carrying capacity and could complete the cleaning process in a short time. The flap filter adopts the principle of segmented direct flushing to discharge sewage. When sewage is discharged under more suitable working conditions, the two sewage discharge stages can quickly and effectively clean the entire filter surface to ensure normal filtration in the next cycle. Meanwhile, combining theoretical analysis and experimental analysis, the best effect can be achieved by using a high inlet flow rate for a short time, which can meet the smaller water consumption and shorter drainage time requirements at the same time. Therefore, it is suggested that the relevant conclusions can be applied to guide the use of the same type of mesh filter in actual projects.

\section{CONCLUSIONS}

(1) In the sewage discharge process, the inlet sand content had a much lower impact on the sewage discharge process than the inlet water flow rate. As the inlet water flow rate increased, the sewage discharge time was reduced, the required time for the pressure difference to reach a stable value was reduced in both the first discharge stage and the second discharge stage, and the cleanliness of the sewage was improved. When the flow rate was lower than $160 \mathrm{~m}^{3} \mathrm{~h}^{-1}$, the sewage discharge time was in the range of 63-69 s, and the time for the pressure difference to reach a stable value was 17-24 s and 12-20 s for the first discharge stage and the second discharge stage, respectively. When the flow rate was greater than $160 \mathrm{~m}^{3} \mathrm{~h}^{-1}$, the sewage discharge time was $48-53 \mathrm{~s}$, and the time required for the pressure difference to reach a stable value was 14-25 $\mathrm{s}$ and 12-19 $\mathrm{s}$ for the first sewage discharge stage and the second discharge stage, respectively. The sewage cleanliness $\varphi$ was greater than $90 \%$.

(2) Combining the mass conservation law and the sewage discharge experimental results, mathematical expressions of the sewage discharge time, the pressure difference of the sewage discharge, and the cleanliness of the sewage were developed. The equations were verified by comparing the experimental data of the sewage discharge process with the fitted results by the formula. From the comparison, the fitted calculation results were consistent with the experimental results. To ensure that the filter can meet the requirements of smaller sewage consumption and a higher sewage effect, it is recommended to control the discharge flow rate at 180 $\mathrm{m}^{3} \mathrm{~h}^{-1}$ and set the sewage discharge time to $50 \mathrm{~s}$, under which conditions a $98 \%$ cleanliness can be achieved.

\section{ACKNOWLEDGEMENTS}

We thank the National Natural Science Foundation of China (No. 11662018).

\section{REFERENCES}

Bounoua S, Tomas T, Labille J, Molle B, Granier J, Haldenwang P, Izzati SN (2016) Understanding physical clogging in drip irrigation: in situ, in-lab and numerical approaches. Irrigation Science 34(4): 327-342. DOI: https://doi.org/10.1007/s00271-016-0506-8

Bové J, Arbat G, Duran-Ros M, Pujol T, Velayos J, Cartagena FR de, Puig-Bargués J (2015) Pressure drop across sand and recycled glass media used in micro irrigation filters. Biosystems Engineering 137: 55-63. DOI: https://doi.org/10.1016/j.biosystemseng.2015.07.009

de-Deus FP, Mesquita M, Testezlaf R, de-Almeida RC, de-Oliveira HFE (2020) Methodology for hydraulic characterisation of the sand filter backwashing processes used in micro irrigation. Biosystems Engineering 192:188-198. DOI: https://doi.org/10.1016/j.mex.2020.100962

de-Vito R, Pagano A, Portoghese I, Giordano R, Vurro M, Fratino U (2019) Integrated approach for supporting sustainable water resources management of irrigation based on the WEFN Framework. Water resources management 33(4):1281-1295. DOI: https://doi.org/10.1007/s11269-019-2196-5

Duran-Ros M, Puig-Bargués J, Arbat G, Barragán J, Cartagena FR de (2009) Performance and backwashing efficiency of disc and screen filters in microirrigation systems. Biosystems Engineering 103(1): 35-42. DOI: https://doi.org/10.1016/j.biosystemseng.2009.01.017

Elbana M, De Cartagena FR, Puig-Bargués J (2013) New mathematical model for computing head loss across sand media filter for microirrigation systems. Irrigation Science 31(3): 343-349. DOI: https://doi.org/10.1007/s00271-011-0310-4

Elbana M, De Cartagena FR, Puig-Bargués J (2012) Effectiveness of sand media filters for removing turbidity and recovering dissolved oxygen from a reclaimed effluent used for micro-irrigation. Agricultural Water Management 111:27-33. DOI:

https://doi.org/10.1016/j.agwat.2012.04.010 
García-Nieto PJ, García-Gonzalo E, Puig-Bargués J, Duran-Ros M, de-Cartagena FR, Arbat G (2020) Prediction of outlet dissolved oxygen in micro-irrigation sand media filters using a Gaussian process regression. Biosystems Engineering 195:198-207. DOI: https://doi.org/10.1016/j.biosystemseng.2020.05.00910.

García-Nieto PJ, García-Gonzalo E, Arbat G, DuranRos M, de Cartagena FR, Puig-Bargués J (2018) Pressure drop modelling in sand filters in micro-irrigation using gradient boosted regression trees. Biosystems Engineering 171: 41-51. DOI: https://doi.org/10.1016/j.biosystemseng.2018.04.011

García-Nieto PJ, García-Gonzalo E, Arbat G, Duran-Ros M, de-Cartagena FR, Puig-Bargués J (2016) A new predictive model for the filtered volume and outlet parameters in micro-irrigation sand filters fed with effluents using the hybrid PSO-SVM-based approach. Computers and Electronics in Agriculture 125:74-80. DOI: https://doi.org/10.1016/j.compag.2016.04.031

Hamududu BH, Ngoma H (2020) Impacts of climate change on water resources availability in Zambia: implications for irrigation development. Environment Development and Sustainability 22(4): 2817-2838. DOI: https://doi.org/10.1007/s10668-019-00320-9

Li JS, Fei LJ, Li S, Shi ZX, Liu LH (2020) The influence of optimized allocation of agricultural water and soil resources on irrigation and drainage in the Jingdian Irrigation District, China. Irrigation Science 38(6):37-47. DOI: https://doi.org/10.1007/s00271-019-00649-z

Li M, Liu ZJ, Shi K (2019) Experimental Study on Sewage Discharge Effect of Drip Irrigation Net Filter. Journal of Irrigation and Drainage 38(10): 55-62. DOI: https://doi.org/10.13522/j.cnki.ggps.20190265

Li QQ, Zong QL, Liu ZJ, Lan Jun (2014) Experiment and calculation of discharge time for horizontal type self-cleaning screen filter. Journal of Drainage and Irrigation Machinery Engineering 32(12): 1098-1104.

Liu QJ, Chen T, Chen SC, Liu Q (2009) Approximate calculation formula of the normal distribution integral and its application in the determination of experimental results. Modern Measurement and Laboratory Management (3): 21-23. DOI:

https://doi.org/10.16428/j.cnki.cn11-4827/t.2009.03.002

Liu ZC (1991) Calculation of Sand Carrying Capacity of Water Flow in Pressurized Irrigation Pipelines. Farmland Water Conservancy and Small Hydropower (10): 9-11.

Liu ZJ, Shi K, Li M, Wen XY, Xie Y (2019) Experimental Study on Head Loss of Vertical and Horizontal Self-cleaning Mesh Filter. Journal of Irrigation and Drainage 38(12): 44-50. DOI: https://doi.org/10.13522/j.cnki.ggps.2019005
Mesquita M, de-Deus FP, Testezlaf R, da-Rosa LM, Diotto AV (2019) Design and hydrodynamic performance testing of a new pressure sand filter diffuser plate using numerical simulation. Biosystems Engineering 183:58-69. DOI:

https://doi.org/10.1016/j.biosystemseng.2019.04.015

Martí P, Shiri J, Duran-Ros M, Arbat G, de Cartagena FR, Puig-Bargués J (2013) Artificial neural networks vs. Gene Expression Programming for estimating outlet dissolved oxygen in micro-irrigation sand filters fed with effluents. Computers and Electronics in Agriculture 99:176-185. DOI:

https://doi.org/10.1016/j.compag.2013.08.016

Piecuch T, Piekarski J, Malatyńska G (2013) The Equation Describing the Filtration Process with Compressible Sediment Accumulation on a Filter Mesh. Archives of Environmental Protection 39(1): 93-104. DOI: https://doi.org/10.2478/aep-2013-0009

Puig-Bargués J, Barragán J, de Cartagena FR (2005) Development of Equations for calculating the Head Loss in Effluent Filtration in Microirrigation Systems using Dimensional Analysis. Biosystems Engineering 92(3):383-390. DOI: https://doi.org/10.1016/j.biosystemseng.2005.07.009

Rashid K, Jasur M, Jilili A, Bakhtiyor K (2020) Challenges for the sustainable use of water and land resources under a changing climate and increasing salinization in the Jizzakh irrigation zone of Uzbekistan. Journal of Arid Land 12(01):90-103. DOI: https://doi.org/10.1007/s40333-020-0092-8

Shi K, Liu ZJ, Li M (2020) Experimental study on head loss of a new type of rotatable plate screen filter. Journal of drainage and irrigation machinery engineering 38(4): 427-432

Song JP (2017) Study on the optimal drainage time of the self-cleaning screen filter. Yellow River 39(3): 145-148.

Yurdem H, Demir V, Degirmencioglu A (2010) Development of a mathematical model to predict clean water head losses in hydrocyclone filters in drip irrigation systems using dimensional analysis. Biosystems Engineering 105(4): 495-506. DOI: https://doi.org/10.1016/j.biosystemseng.2010.02.001

Zong QL, Liu ZJ, Liu HF, Yang HF (2019) Backwashing performance of self-cleaning screen filters in drip irrigation systems. PloS one 14(12). DOI: https://doi.org/10.1371/journal.pone.0226354

Zong QL, Zheng TG, Liu HF, Li CJ (2015) Development of head loss equations for self-cleaning screen filters in drip irrigation systems using dimensional analysis. Biosystems Engineering 133: 116-127. DOI: https://doi.org/10.1016/j.biosystemseng.2015.03.001 